\title{
Defining "Social Sustainability": Towards a Sustainable Solution to the Conceptual Confusion
}

\author{
Karl de Fine Lichta ${ }^{\mathrm{a}}$, Anna Folland ${ }^{\mathrm{b}}$ \\ ${ }^{a}$ Chalmers University of Technology, karl.definelicht@chalmers.se \\ ${ }^{b}$ Department of Philosophy, Uppsala University, anna.folland@filosofi.uu.se
}

DOI: http://dx.doi.org/10.5324/eip.v13i2.2913

(cc)BY

This is an open access article distributed under the terms of the Creative Commons Attribution 4.0 International License, which permits unrestricted use, distribution, and reproduction in any medium, provided the original author and source are credited.

The interest in "social sustainability" has recently increased in the field of urban development. We want societies, cities, and neighborhoods to be economically and environmentally sustainable, but we also want urban areas that are safe, diverse, walkable, and relaxing, just to mention a few examples. Strikingly, however, there is no consensus regarding what definition of "social sustainability" should be employed. Additionally, some people are skeptical about the prospect of finding a useful definition at all and claim it is impossible to satisfactorily define the concept for various reasons, such as its complexity. A potential first step towards navigating this conceptual maze is to provide desiderata for a definition of social sustainability. We defend a list of nine desiderata and thereby create a theoretical framework for analyzing and constructing a definition of "social sustainability". We also examine the skeptical arguments and find that it is premature to conclude that the goal of finding a useful definition is hopeless. With the criteria in place, the future debate can proceed by assessing definitions of "social sustainability" in a more structured and transparent manner. This activity is of upmost importance if we want to create just cities.

Keywords: Social Sustainability, Definition, Purposes and Aims, Conditions of Adequacy

\section{Introduction}

For a little over thirty years, there has been a great push for sustainability. As the Brundtland Commission famously stated, "Sustainable development is development that meets the needs of the present, without compromising the ability of future generations to meet their own needs" (Brundtland et al. 1987: 29). In response, many tools and certifications, purported to yield environmentally - and economically sustainable processes and outcomes, have been developed (e.g., Mjörnell et al. 2015).

Three forms of sustainability are generally recognized: environmental, economic, and social. In recent years, social sustainability has received considerable attention in urban development, in cities and in societies as a whole (e.g., Pitts 2004, Bramley and Power 2009, Dempsey et al. 2011, Ghahramanpouri et al. 2013). ${ }^{1}$ When starting large 
renovation projects or building new neighborhoods, those in charge often say that such projects should not only be environmentally and economically sustainable but also socially sustainable. Thus, different types of tools and certifications have begun to incorporate this dimension of sustainability. For example, the highly influential certification of environmental sustainability, LEED, now has a cousin, WELL, that focuses on social sustainability. ${ }^{2}$ Depending on one's ambition, this tool has ascending levels of certification - silver, gold, and platinum (the most ambitious).

However, several obstacles crop up when working with social sustainability issues. The most significant of these is the wide array of definitions of "social sustainability," both in the sciences and in practice, with none being universally accepted (e.g., Murphy 2012, Ghahramanpouri et al. 2013, Boström 2015). The potential negative effects of lacking a clear definition are manifold. Drawing from our experience of working with social sustainability issues in collaboration with municipalities, entrepreneurs, and others for many years, new actors always ask how to define this key term. With no universally accepted answer, gaining trust and confidence in the project is a steep uphill battle. More generally, the lack of a definition seems to make it easier for strong actors to push through their own agendas under the guise of social sustainability (e.g., McKenzie 2004: 12-25), which can result in outcomes that are less equitable and advantageous for all (Boström et al. 2015: 136-138). These examples reflect the downside of lacking a universally accepted definition of "social sustainability".

The discussion about how to define this term is severely hampered by not having common ground for defining the concept. This shortcoming results in definition proposals that are radically different in content. For example, some people argue in favor of a simple concept that defines "social sustainability" in value-neutral terms (e.g., Beckerman 1994), while others argue for a value-laden and complex concept, such as Barron and Gauntlett, who contend that

[s]ocial sustainability occurs when formal and informal processes, systems, structures and relationships actively support the capacity of future generations to create healthy and livable communities. Social sustainable communities are equitable, diverse, connected and democratic and provide a good quality of life (Barron and Gauntlett 2002). ${ }^{3}$

Beckerman, on the other hand, even though he does not formulate an explicit definition, concludes that "'sustainability' should be interpreted as a purely technical characteristic of any project, program, or development path, not as implying any moral injunction or over-riding criterion of choice" (Beckerman 1994: 205). The argument in favor of keeping the definition simple is often that it is too hard to measure whether we have reached sustainability goals if the definition is too complex. However, those in favor of a complex definition worry about losing important values by developing a simple definition. Thus, different grounds for what constitutes a good definition yield different results in terms of the definition's content.

Although finding common ground is crucial for producing a rationally agreedupon definition, there has been no comprehensive discussion of the basis for assessing the definitions. In this paper, we will provide a list of desiderata for a definition of "social sustainability", thereby furnishing the debate with clear grounds for testing definitions, including bringing out their advantages and disadvantages. This will take the debate a step forward by narrowing the broad spectrum of reasonable definitions. We also aim to refute some skeptical arguments against the 
project of finding a useful and universal definition. This is of great practical importance, since people may believe that "anything goes" if the skeptics win. In turn, we risk a future where grossly unjust outcomes are portrayed as socially sustainable.

In this paper, we first outline the purposes of defining "social sustainability". We then formulate and defend a theoretical framework for analyzing and constructing a definition of this term. The framework consists of nine conditions of adequacy (desiderata) that appeal to the purposes of defining "social sustainability". ${ }^{4}$ Finally, we discuss objections to some of the specific conditions, as well as skeptical arguments against defining "social sustainability". ${ }^{5}$

\section{Purposes and conditions of adequacy}

This section consists of two parts: the first discusses the purposes of defining "social sustainability" in more detail, and the second formulates conditions of adequacy for such a definition. The purposes will in part help determine the conditions and what weight we should attribute to them. The final portion of this section makes some general remarks on how the desiderata should be used to assess different definitions and what factors come into play in such assessments.

\section{Purposes of defining "social sustainability"}

It is often said that no "blueprint definition" of "social sustainability" (Weingaertner and Moberg 2014) can be found. This means that there is no single definition of the term, irrespective of field or underlying purpose. One might take this as a skeptical argument against the project, but it is not. In fact, it seems quite evident that a definition of "social sustainability" must be relative to the purposes we have for it, and when these purposes are determined, we might find a definition upon which people who are rational, informed, and reasonably open-minded could agree. For this reason, the purposes are explicitly discussed in this paper.

The main purpose of defining "social sustainability" is a practical one. We want to produce good and fair results through good and fair processes when developing our cities. This is quite hard considering the range of different agents involved in these highly complex situations (e.g., Boström et al. 2015: 136-138). However, a definition of "social sustainability" could make it easier to achieve the desired result. Assuming the definition is well devised, it should, broadly speaking, be a "criterion of rightness" for different forms of decision-making models. The definition should serve as a foundation for the tools that policymakers use when trying to achieve socially sustainable results, as well as for scientists examining how this can be done.

The concept of "social sustainability" that we are interested in is applied in a broadly democratic context, and the definition can thus be thought to have a (practical) democratic purpose. In democracies, we want to be able to discuss our mutual problems with a minimum of misinterpretations. In particular, we want citizens to be able to grasp what the discussion concerns. Hence, it is desirable to use language that is accessible to laypersons, meaning those who are not closely involved in urban development processes. That a definition and the reasons for it are clear and transparent is also beneficial, because then ordinary people can understand what policymakers and those in the industry are discussing in greater detail.

The other purpose for defining "social sustainability" is both theoretical and practical. Scientists need a definition they can use when conducting research on how 
to achieve socially sustainable results; it would be helpful if decision-makers and the entire research community employed the same definition. People working on the practical side are often inspired by research, and researchers often depend on practitioners for the information they need to produce good scientific work. Hence, "speaking the same language" - including using the same definition - would be useful for researchers and practitioners alike.

Before moving on, it is important to clarify what we mean by "definition." ${ }^{\prime}$ It is sometimes argued that what is labeled a definition here is in fact also a tool (e.g., Moula and Sandin 2015). For example, according to one definition of "tool,"

[a]n ethical tool is a practical method and/or conceptual framework with the main purpose of helping the user(s) improve their ethical deliberations in order to reach an ethically informed judgment or decision (Moula and Sandin 2015: 264).

The difference between a tool and a definition (as used here) is that a definition should have a general application in the context of social sustainability work in urban development. Tools, on the other hand, should be developed for specific tasks. One might object that the definition of "social sustainability" will be too broad if it is to serve general purposes (e.g., Ghahramanpouri et al. 2013: 186). However, this seems to be the case only if one wants to use the definition as a tool, which is not intended here.

In the interest of formulating a comprehensive foundation for work on social sustainability, tools (in contrast to definitions) need to be specific in at least two ways. First, we require different tools for different processes. For example, if a city wants to build on a vacant lot, it requires a very different tool from the one needed for subsequently managing the actual buildings erected on the spot. Second, a tool's development needs to depend on its intended use, for example, whether it is meant to justify a decision, motivate public engagement, or achieve procedural fairness (Moula and Sandin 2015: 273-276). This level of specificity is not required from a definition; rather, we want the same definition of "social sustainability" across such usages. For instance, we want to be talking about the same thing when we justify a decision connected to social sustainability as when we motivate public engagement that relates to social sustainability.

More generally, a definition should provide a common aim for all relevant levels, from the micro-level (e.g., the individual building or neighborhood) to the macrolevel (e.g., the region or country), as well as the different types of districts that exist (e.g., central business district, historic district, urban place) (e.g., Ghahramanpouri 2013: 189f). The definition needs to be general enough to guide work on all levels and obtain a unified account of "social sustainability" that can be used to develop specific tools for various purposes. Consequently, we do not argue here that there is a difference in ontological status between tools, which serve the purpose of creating socially sustainable outcomes, and definitions, which are used to determine whether the tool generates a socially sustainable outcome. Rather, we claim that two functions are needed here: tools are employed for specific purposes, while definitions are used for more general purposes. Figure 1 provides a picture of how purposes, adequacy conditions, definitions and tools relate to one another. 


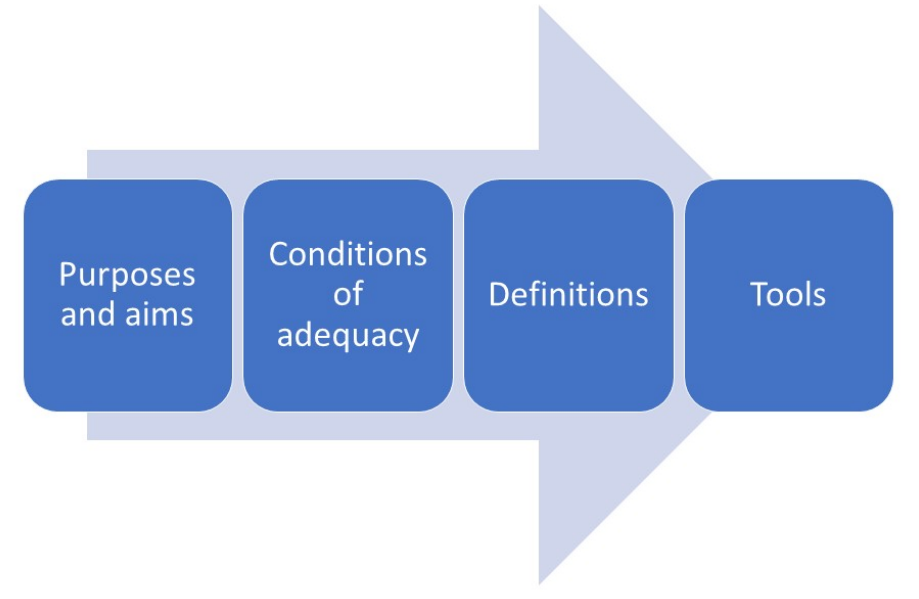

\section{Conditions of adequacy for a definition of "social sustainability"}

To fulfill the purposes above, a definition should capture how we talk and what we value. It should also be clear, without overall adverse effects when implemented. We will discuss nine conditions that constitute the theoretical framework for analyzing and constructing a definition of "social sustainability". This is not to imply that the list is exhaustive, and fulfilling the conditions should be seen as a desirable goal of a definition, rather than an absolute requirement. It is possible that no definition can satisfy all conditions. Moreover, satisfying a condition is a matter of degree. Definitions will likely satisfy the conditions to varying extents; and if so, we should use the definition that fulfills the most important conditions to the highest degree. ${ }^{7}$

\section{Ordinary language}

The first condition is the ordinary language condition. ${ }^{8}$ It is desirable for a definition of "social sustainability" to be consistent with how the term is ordinarily used. ${ }^{9}$ This includes how it is employed (although not necessarily defined) by social scientists, practitioners in urban development and, to some extent, people in general. ${ }^{10}$

For example, in Edinburgh, a study showed great health and lifespan disparities among people living along the same tramline. ${ }^{11}$ In turn, this has led many to condemn cities like it for being fully or partially socially "unsustainable" (e.g., Dempsey et al. 2011: 291f). If these intuitive judgments survive scrutiny, our definition of "social sustainability" should be compatible with this usage of the concept. Barron and Gauntlett's (2002) definition (described in the introduction), for instance, is reasonably in line with these judgments, since it seems that the community is not equitable and fails to provide a good life for everyone.

There are several reasons for having a definition correlate with ordinary usage. Satisfying this condition helps avoid misusage and misunderstanding. First, it is hard to relinquish the initial intuitive understanding of a term. Therefore, the term risks being misused if it fails to adhere to ordinary usage, even after being explicitly redefined. Second, in work on risk assessment, for instance, policymakers have been found to often misinterpret different sorts of risk analyses conducted by scientists and experts (e.g., Hansson 2018). ${ }^{12}$ One explanation for this misinterpretation concerns the definitions of "risk." Scientists and experts use a technical definition that differs from the ordinary understanding of the term. 
Another fact, which supports the ordinary language condition, is that scientific jargon makes facilitating a non-hierarchical relationship between the public and experts harder (e.g., Dillard et al. 2009, Boström et al. 2015). Inaccessible terminology can have detrimental effects on all processes involving the public. Using a term that deviates from ordinary language makes it more difficult, or even impossible, to successfully collect required information and engage citizens. Hence, the processes risk being less democratic and, in this sense, less legitimate if they rely on a definition that fails to satisfy the ordinary language condition.

Ideally, a definition should also help explain our intuitive judgments concerning social sustainability. We should preferably be able to explain (1) our judgments about certain cases being prime examples of social sustainability or unsustainability, (2) our disagreement and uncertainty about whether a city or neighborhood is socially sustainable, and (3) our comparative judgments about social sustainability.

For example, Barron and Gauntlett's (2002) definition could explain why most people judge Cape Town to be socially unsustainable, why it is less socially sustainable than the city of Gothenburg in Sweden, and why people might disagree about whether Gothenburg actually is socially sustainable. While Cape Town is a diverse city, it does not fulfill any criteria provided by the aforementioned definition, which accounts for the judgment that the city is unsustainable. Gothenburg fulfills the criteria much better than Cape Town, which explains the judgment that Gothenburg is more socially sustainable than Cape Town. However, Gothenburg has a lot of problems as well, which yields both optimistic and pessimistic opinions concerning what the future holds in terms of equity, well-being and other criteria. In other words, some individuals judge the city to be socially sustainable, while others disagree.

Good reasons exist for thinking that a definition should also explain the common core of our social sustainability judgments, sometimes called the "unity desideratum" (e.g., Bradley 2012: 395). First, we want to be able to provide arguments in favor of our views and against others' opinions when it comes to urban development. To ensure a transparent process, we must have access to the fundamental building blocks of our judgments regarding social sustainability. We acquire this basis through explaining our beliefs about different cases. Of course, "justification" should not be conflated with "explanation." For instance, even if the justification for our judgments about social sustainability is poor, the underlying explanations can still give us access to reasons we would otherwise lack.

Second, from a pedagogical standpoint, it is more desirable to present a definition that can explain a series of instances, rather than attempt to teach someone the entire body of cases or outcomes of a certain kind. This is partly because it facilitates discussion between people from different backgrounds, professions, and positions (e.g., Brülde 2003: 58). ${ }^{13}$ It is easier to formulate a more fundamental and accessible idea than to list a range of instances considered good and just, although the latter is quite common in the current debate (e.g., Ghahramanpouri et al. 2013). The point is that having a definition of "social sustainability" that operates through fundamental principles enables us to apply the principles through generalizations about cases and through predictions.

In the discussion about how "social sustainability" should be defined, there are many definitions that arguably should be disregarded or modified because of their failure to meet the ordinary language criterion. Specifically, such definitions do not correlate with ordinary language use and/or do not offer a unified core. However, 
many definitions of "social sustainability" could be reduced to a common core. In particular, research overviews identify a range of related themes, such as justice, culture, democracy, integration (Weingaertner and Moberg 2014), well-being, life satisfaction, social cohesion (Ghahramanpouri et al. 2013), social equity, quality of life (Ghahramanpouri et al. 2013; Weingaertner and Moberg 2014), social inclusion, participation, and place identity (Gustavsson and Elander 2013, 2014). The common core here could be well-being, which is often perceived in philosophical and psychological literature as "life satisfaction" and "quality of life." ${ }^{14}$ For instance, if social cohesion were bad for us, then we would likely not value it. Hence, the value of social cohesion seems reducible to that of well-being - of course, this is just one of many examples.

\section{Coherence, precision, reliability, measurability, and simplicity}

Policymakers and practitioners need a concept that can be systematically applied and that is sufficiently clear and precise. For instance, previous work on a collaborative research project including building entrepreneurs has shown that entrepreneurs have lost contracts because of the various interpretations of "social sustainability". They have simply misunderstood what the client meant by the term. ${ }^{15}$ More generally, according to many of the management regimes, such as SMART, we need to be specific about our goals if we are to achieve them (e.g., Doran 1981).

Similarly, when politicians want to "sell" their vision to the public, there is democratic value in the public understanding what the politician wants to sell. Politicians probably also strive for a somewhat clear picture of their own visions. A reasonably clear definition helps us avoid what is sometimes called "policymakers' escapism," which hides the complexity underneath all the "sustainababble" (Engleman 2013: 3). This trap is easy to fall into when politicians, as well as the general public, lack a clear understanding of the term.

Thus, for people to communicate effectively and make good (and democratic) decisions, the concept must be fairly clear and precise. However, we are not saying that any definition that is precise is preferred over a definition that is less so (compare this to the criticism of different "new public management" regimes in Power 1997 and Bevan and Hood 2006). Instead, a definition should be clear and precise while also fulfilling the other conditions. If the definition cannot successfully do both, these shortcomings must be weighed against each other.

In addition to ordinary language, there are five more conditions of adequacy that relate to the considerations just discussed. First, we have the coherence condition, which simply states that a definition should be logical and consistent. Otherwise, it is difficult to even talk about social sustainability in a general manner. We are striving for a coherent set of defining features, such that a specific state is never both socially sustainable and not socially sustainable. In ordinary language, "social sustainability" might have a meaning that yields this sort of incoherent result. Our concepts are often vague and not thoroughly considered, even if they are in fact used in policy contexts. Consider the terms "health" and "disease." These are not clearly defined in settings where policy is construed, and their meaning is presumably even less clear in ordinary language. If the ordinary usage of "social sustainability" is vague and incoherent in this way, we need to ask ourselves if coherence or adherence to ordinary language carries more weight. The goal should probably be to find a coherent definition as close to the ordinary language use as possible. 
In a sense, the coherence condition is a precondition for the next two criteria, the precision condition and the reliability condition. According to the precision condition, a definition should be sufficiently clear and precise to, in principle, determine if a given state (e.g., outcome, process, city) is socially sustainable. In other words, there should be little doubt (ideally no doubt) as to whether a certain state is an instance of social sustainability. What it takes to satisfy the condition depends on whether the approach is categorical or dimensional. If we think of social sustainability as a category (i.e., determined by a certain (high) level of social sustainability), a definition should draw a sharp conceptual boundary between social sustainability and other desirable states, such as environmentally and economically valuable states. If we adopt a dimensional approach rather than (or in addition to) a categorical approach, the condition requires being able to determine whether an attitudinal (or other) change constitutes an improvement in social sustainability, a reduction in social sustainability, or neither. ${ }^{16}$

The reliability condition states that a definition should be practically applicable. It should be relatively easy, in practice (not just in principle), to determine whether a state is socially sustainable, or whether it is more or less socially valuable than another state. A concept that satisfies this condition enables different actors to apply the concept in the same way; for example, they might agree on what to exclude from the category of "social sustainability". This condition is likely satisfied if the criteria for applying the concept are operational, which means the concept is defined in observational terms, and its presence can be established on observational grounds. Practical applicability is obviously important for communication purposes; a definition that satisfies this condition can (if commonly accepted) improve or facilitate communication between different groups and individuals, both within and across settings and cultures.

The next two conditions, the measurability condition and the simplicity condition, relate to each other, and to the greater question of assessing degrees of social sustainability in a transparent and systematic manner. According to the measurability condition, a definition should ideally make it possible to compare different levels of social sustainability, meaning that social sustainability is measurable in the ordinal sense. This holds for comparisons that are interpersonal, intrapersonal, and intertemporal.

However, a plausible concept of social sustainability likely does not allow for cardinal measurability, since some social values by which we measure social sustainability, such as attitudes, are not measurable in such a strong sense (e.g., Haybron 2016, Bykvist 2016). Furthermore, we believe that the measurability condition cannot be satisfied to a high degree unless the following simplicity condition is satisfied: the class of states (e.g., attitudes) categorized as examples of social sustainability should be as homogenous as possible. This suggests that, other things being equal, we should prefer a theory that defines "social sustainability" in terms of one criterion only, or in terms of a conjunction of different criteria, to a theory that defines it in terms of a disjunction of different criteria. This also means that we have reason to aim for a monistic definition of "social sustainability" instead of a pluralistic one. The simplicity condition would thus not support complex definitions, which include some of the most common definitions, such as that of Barron and Gauntlett (2002). 


\section{Normative adequacy and value}

Three conditions remain in our discussion of a good definition: the value condition, the condition of normative adequacy, and the amorality condition. ${ }^{17}$

The value condition is based on the idea that a good definition ought to help explain why we have value-based reasons to promote social sustainability and combat social unsustainability. ${ }^{18}$ For instance, we have reason to alleviate health disparities in a city because they, ceteris paribus, are unfair. Most participants in the debate on social sustainability believe that achieving it has positive value and that socially unsustainable communities are at risk (e.g., McKenzie 2004: 13; see also Vallance et al. 2011: 346, who support the value condition explicitly). In this sense, the value condition can be considered a special case of the ordinary language condition simply because, according to ordinary usage, social sustainability has positive value. To be clear, this implies that a definition of "social sustainability" that is not value laden in accordance with Beckerman's (1994) claim - fails to satisfy the value condition and is flawed in this respect. ${ }^{19}$

The evaluative judgments, with which the definition should be in line, are plausibly well-considered judgments, such that they reflect what we hold after some reflection. As with the ordinary language criterion above, the idea is that we should give considerable thought to what we believe is good and right. Then we can employ these conclusions to assess the definition of "social sustainability". Using different types of examples (or even thought-experiments) can help us determine the definition's implications.

The classic argument in favor of eating meat can help us understand why we should use well-considered judgments. Consider the argument that "it is permissible to eat meat because we have always done so." After a bit of reflection, many of us would reject this argument. Throughout history, many horrors have resulted from what we "have always done," such as subjugating women, slavery, and torture. A wellconsidered case in favor of eating meat thus cannot be based solely and without qualification on this argument.

In addition, there are value-laden and pragmatic reasons to use well-considered judgments when defining "social sustainability". ${ }^{20}$ In relation to value-laden reasons, employing well-considered judgments can be regarded as desirable because it means using justified judgments when reflecting on how we should structure our society. Well-considered judgments are often more justified and (perhaps) closer to the truth (e.g., McMahan 2013: 111-115, Tännsjö 2015: 1-18).

Promoting social sustainability measures is arguably easier from a pragmatic standpoint if the concept is based on well-considered judgments, because the reasons for using such a concept are stronger than for one based on immediate gut reactions. Policies that rely on a definition founded on well-considered judgments will possibly be both more stable and more acceptable over the long term. Moreover, the reasons for using such a definition will be much clearer to decision-makers. Of course, the potential problem with using well-considered, instead of spontaneous, judgments is that the definition of "social sustainability" moves away from the ordinary use of the term. However, this is probably a reasonable price to pay for the benefits - such as greater stability and higher value - related to using well-considered judgments.

The condition of normative adequacy stems from the idea that a definition of "social sustainability" should help us make better decisions. This requires the concept to work well when applied in practice. The results of applying the concept should be 
good and just, according to plausible normative views. For example, residents in a neighborhood identified as socially unsustainable might feel highly stigmatized. This might lead to less, rather than more, social sustainability being generated when applying a certain concept. The normative adequacy condition is therefore probably one of the most important criteria for devising a definition of "social sustainability" from a practical standpoint. Neither should the term be defined in such a way that it has the same extension as another concept, because that would make it redundant or ineffective. For instance, if our definition of "social sustainability" selects the same states as our definition of "justice," then that definition of "social sustainability" does not help us make better decisions, since we already have another concept fulfilling the same function.

Finally, it seems reasonable that identifying an outcome as socially sustainable is not an all-things-considered moral reason for bringing about that outcome, but rather, if anything, a pro tanto moral reason. The definition of "social sustainability" should not conceptually presuppose that bringing about a socially sustainable outcome is always morally right. This final desideratum is often called the amorality condition. Of course, one could have an ethical view that it is always morally right to bring about socially sustainable outcomes, but that view seems highly questionable. (For example, imagine if the only way to bring about social sustainability was to sacrifice the lives of innocent people.) Moreover, the question of what role social sustainability plays in ethical theory should not be confused with (or built into) the conceptual question of how to define the term. ${ }^{21}$ In conclusion, the amorality condition requires that social sustainability does not entail moral rightness, and a definition that fulfills this can be consistent with different ethical principles describing the moral status of social sustainability.

The above considerations imply, first, that it is not always morally right to bring about socially sustainable outcomes, since there are other morally relevant factors than social sustainability. For instance, imagine someone with libertarian beliefs who thinks that outcome A would be more socially sustainable than outcome $\mathrm{B}$, but achieving A would necessarily involve forcing people to pay more taxes. In the libertarian's opinion, we should choose A only if we have everyone, or most people, on board with paying more taxes (i.e., we should not force people to pay taxes). Since enforcing increased taxes is morally unacceptable, the libertarian concludes that although A is desirable in terms of social sustainability, given the circumstances, we have an all-things-considered moral reason to opt for $\mathrm{B}$. According to her, this is true at least until we have everyone, or most people, on board with the tax increases in A.

Second, a normatively adequate definition of "social sustainability" needs to accommodate the fact that social sustainability judgments on different levels of analysis do not need to converge. For example, it is sometimes argued that for a region to be socially sustainable, certain key services, such as primary schools, banks and pubs, need to be located close to residents (e.g., Dempsey 2009: 292f). Consider a place where very few people live and where maintaining these services is costly. We would see a strong tension between residents here and those living in other less resource-consuming areas. In this case, it is reasonable to say that we have a socially sustainable hamlet (because of the local facilities), but we have a socially unsustainable region (because of the tension between the different areas).

Third, it is desirable that a definition does not conflict with major international ambitions and treaties, such as those of the United Nations (UN), the European 
Union (EU), or similar large-scale governing bodies. A definition that conflicts with such ambitions and treaties is less likely to be used, and there is an increased risk that its positive effects will be nullified. For example, according to Murphy (2012: 19f), this means that we should include linkages to environmental sustainability in the definition of "social sustainability". This is because it could shed valuable light on sustainability as such and it is sought after in key documents, such as the UN Commission for Sustainable Development (UNSD 1996) and EU Sustainable Development Indicators (Eurostat).

To summarize, we have nine conditions of adequacy that form our theoretical framework for defining "social sustainability": ordinary language, coherence, precision, reliability, measurability, simplicity, value, normative adequacy, and amorality. A definition that fails to satisfy these conditions warrants questioning, or revising, it, as shown in Figure 2 below.

Figure 2

\section{Definition: "Social sustainability" is X}

\section{Desiderata}

The ordinary language condition
The coherence condition
The precision condition

The reliability condition

The measurability condition

The simplicity condition

The value condition

The condition of normative adequacy

The amorality condition

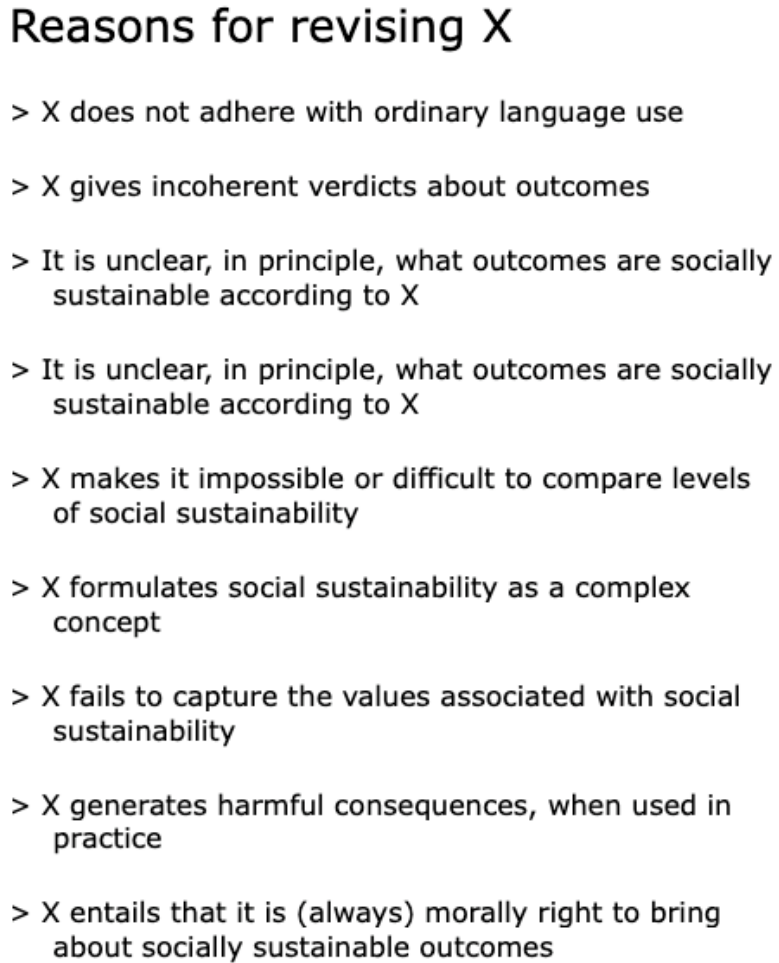

As the figure illustrates, failing to fulfill the desiderata gives us reason to question the usefulness of the definition, and therefore, to revise it. Similarly, if a definition satisfies a condition, it can be thought of as a reason for favoring, or employing, it. Another important aspect when assessing definitions is to what extent the definition satisfies a condition. The strength of reasons for and against definitions will depend on the extent to which they do or do not satisfy the desiderata. For example, assessments and comparisons of definitions will likely involve definitions that are precise to different degrees. If two definitions are highly precise, but one is even more precise than the other, then this weighs in its favor. 
In addition, the strength of reasons for and against definitions plausibly depends on the importance of the desiderata they do or do not satisfy. For instance, consider a definition that fails to satisfy the precision and normative adequacy conditions to an equivalent degree. We should not assume that these failures weigh equally heavy against the definition; rather, this depends on the importance of the desiderata. Perhaps the normative adequacy condition should be considered more important given the purposes of defining "social sustainability". The assessment of different definitions should be sensitive to how important the desiderata are in light of the purposes of defining the concept. ${ }^{22}$

\section{Skeptical arguments}

Some people are skeptical about being able to formulate a definition of "social sustainability" that can guide us in practice. It has been argued that all-encompassing definitions are too broad for application in specific contexts (McKenzie 2004: 1). If this sort of skepticism is correct, then the attempt to find a general and useful definition is a waste of time. Such skeptics hint at the possibility that no definition can serve the practical and theoretical purposes outlined in this paper. Other types of skepticism are directed towards the idea that social sustainability should be defined separately from the other notions of sustainability, or against some of the conditions of adequacy we defend here. This section addresses these types of skepticism, including the main objection that finding a universally applicable definition is not possible.

One way to phrase the main objection is that giving "social sustainability" a universal definition cannot succeed, simply because such a definition cannot be true for all (or most) places and times. While many versions of this skepticism exist, we will discuss four here. First, some people argue that we should consider "sustainable" only what results from "dialogue and reflection" (e.g., Jordan 2008: 18f). The skeptic's claim is that a universal definition of "social sustainability" cannot be formulated since, the argument goes, all dialogue and reflection will not yield the same result. ${ }^{23}$

This argument fails because the idea that "social sustainability" should be defined through a process of dialogue and reflection is compatible with there being a universal definition. Notice that not just any dialogue and reflection will suffice to create outcomes that most people would consider socially sustainable. Therefore, the dialogue and reflection process often includes quite specific rules and conditions. Everyone who is affected should have a voice (and those who are not affected should not) is one example of such a guideline. In fact, the criteria for carrying out these processes could be included in a definition of "social sustainability" ${ }^{24}$ Hence, the idea that "social sustainability" should be defined through dialogue and reflection does not necessarily support the skeptic's claim that a universal definition cannot be developed.

Second, some suggest that "social sustainability" cannot be captured in a universal definition because the concept is value laden (e.g., Bijker 1993, Jacobs 1999, Tahvilzadeh 2015), and many people have attempted to develop a definition, but no agreement currently exists (e.g., Ghahramanpouri et al. 2013). Now, even if this rings true, the lack of agreement might be because people are overly pessimistic or because they think that we must do what is socially sustainable. As noted above when discussing the amorality condition, the fact that $\mathrm{X}$ is socially sustainable is (if 
anything) a pro tanto moral reason, not an all-things-considered reason, for producing X. Furthermore, one can question the lack of agreement and argue that people largely do agree about what social sustainability is (e.g., Murphy 2012: 18f).

Third, one could adopt a view of the structure of morality that rules out strict (and general) definitions of any value-laden concept - such as "particularism" (e.g., Dancy 2004). If such a view is correct, and "social sustainability" is a value-laden concept, then the skeptical conclusion would apply to "social sustainability". ${ }^{25}$ In other words, we cannot then formulate a strict, general definition of the term. However, all particularistic views share a common problem. If these judgments about social sustainability were truly particular to the specific context, then we (i.e., almost everyone in any part of the world) would not be able to make judgments - such as "Cape Town is not socially sustainable" - and have roughly the same idea about what it means. However, since we do have a common understanding of this judgement, the idea that social sustainability does not exist in any universal sense seems to violate the ordinary language condition. Hence, this common understanding reveals a drawback of the particularistic view of the concept.

Fourth, some people argue that we should not settle for "one all-encompassing definition" since this "denies much of the concept's complexity" (e.g., Vallence et al. 2011: 345-347). Indeed, many different and conflicting values are at stake. Thus, meeting the ordinary language- and value conditions while simultaneously fulfilling the simplicity condition may not appear doable. This may be true, but a skeptical conclusion seems premature.

For example, one problem with a definition that has a plurality of values is that the values can conflict with each other. Since these values seem so different from each other, they might even be considered incommensurable. This makes it problematic for a definition containing such a plurality of values to be unified and to fulfill the conditions described in the section above. However, in recent years, a great deal of work has been done on incommensurability and how it can be handled (e.g., Temkin 2012, Herlitz and Horan 2017), showing that we could perhaps develop a unified definition with a plurality of values after all. Hence, this skeptical worry does not need to concern us that much. Just because a simple definition may fail to fulfill one of the conditions, it does not automatically follow that the definition should be discarded. There could be decisive normative reasons, for instance, to be revisionist about the concept that amount to giving priority to simplicity, even if a definition does not capture everything the concept embodies.

Another type of skeptical argument targets specific conditions of adequacy. More specifically, some people object to the precision condition we defend here. The basic critical points of the argument seem to be pragmatic reasons against formulating a definition of "social sustainability" or for keeping a definition vague (e.g., McKenzie 2004: 16f, Jordan 2008). For example, according to McKenzie, the most productive way of working with issues of social sustainability is to let the definition and indicators be produced at the local level (McKenzie 2004: 16f). This is thought to yield the best results. Boström and colleagues similarly argue for "conceptual openness" and "interpretative flexibility," which is considered communicatively helpful for actors who deal with contested issues, including those concerning social sustainability (Boström et al. 2015: 132).

However, this approach seems problematic. First, it is not clear that it would be productive to let people define "social sustainability" by themselves. That we will 
achieve socially sustainable outcomes through this process is questionable, considering that many of the most influential actors in this sector - companies - have a strong incentive to promote economic profit. Most often, this means that something buyers perceive to be good is being built, regardless of whether it contributes to a just outcome, all things considered. Letting the actors determine the content of social sustainability by themselves is especially troublesome if we do not already have a comprehensive definition of the term.

Second, it seems that proponents of the conceptual openness and flexibility approach fail to distinguish between what might be called the criterion of conceptual rightness and the decision-making model. The criterion of conceptual rightness, for the definition of "social sustainability" in this case, tells us what a socially sustainable outcome is. The outcome might be constituted in a specific way (such as that everyone has a sufficient share of the resources) or produced in a specific way (such as that everyone had an equal say in the process). The decision-making model, however, describes how we go about achieving what the criterion of rightness prescribes - in this case, social sustainability.

Indeed, as part of a decision-making model it can be argued that, when working with social sustainability issues in a specific context, we need to translate the universal idea of social sustainability into something more concrete. Possibly, a decisionmaking model that is laissez faire, where people can freely define "social sustainability" and its indicators, will produce a more socially sustainable outcome according to the criterion of rightness. However, this does not change what outcomes actually are socially sustainable according to the criterion of rightness. In other words, the idea that precision is desirable for a definition of "social sustainability" (as a criterion of rightness) is compatible with the view that we reach socially sustainable results by utilizing a "conceptually open" or "interpretatively flexible" decisionmaking model.

In conclusion, it is worth noting that a strong skeptical case against the quest to define "social sustainability" is quite difficult to support. Decisively concluding that the project is altogether hopeless requires showing not only that all the current suggestions fail, but also that all possible definitions are doomed to fail. It is something entirely different to claim that formulating an adequate definition is a difficult or complex task. Presumably, many of the non-skeptics in the debate will agree with this claim.

\section{Conclusion}

The social sustainability debate generates many suggestions for how the term should be defined. To fruitfully assess and discuss different definitions, we need a way to identify their respective advantages and disadvantages. This requires a theoretical framework, as formulated through a set of explicit conditions of adequacy, which is what we have introduced and defended in this paper. Without such a framework, the discussion could become skeptical in its outlook for adequately defining "social sustainability", which could in turn lead to grossly unjust results when planning and building our cities. Many of the most influential actors in these processes have reasons to promote building areas that are (perceived as) good only for the people living there, and not areas that are good for everyone affected. If our arguments are plausible, then the skeptical conclusion that it is impossible to formulate a universal definition of 
"social sustainability" is premature. Thus, we conclude that formulating a definition of this term is not an altogether hopeless project.

\section{Notes}

${ }^{1}$ The terms "sustainable," "sustainability," and "sustainable development" are used interchangeably.

2 To read more about the certification, see https://www.wellcertified.com and https://new.usgbc.org/leed. For critical evaluations, see Eken et al. (forthcoming).

3 There is no pagination for this report, which is available here: http://www.regional.org.au/au/soc/2002/4/barron_gauntlett.htm

${ }^{4}$ These conditions of adequacy have been described and defended elsewhere (e.g., Brülde 2000, 2003; for a similar discussion, see also Kagan 1989, Bradley 2012). In this paper, however, the conditions are defended within the context of defining "social sustainability" and modified accordingly. McKenzie (2004: 24) also provides conditions of adequacy. This list, however, is incomplete and the argument in favor of it is insufficient.

${ }^{5}$ In this paper, we discuss social sustainability as an individual concept, separate from other notions of sustainability, such as economic and environmental sustainability. Some argue that we should examine all the dimensions together, including how they relate to each other, instead of considering them separately (e.g., Cuthill 2010, Vallance et al. 2011). The idea that there are different notions of sustainability that are related in different ways does not conflict with any claims put forward in this paper. In fact, studies on the relationships between the notions are surely aided by a reasonably clear definition of "social sustainability" (as well as "economic sustainability" and "environmental sustainability"). However, if the claim is that the dimensions should be combined and captured in one definition, we have reason to suspect that arriving at one comprehensive definition of "sustainability" would be even more complex than individual definitions. Alternatively, creating a simpler definition that captures the conceptual core of "sustainability" (rather than each notion individually), probably requires sacrificing considerable detail, which leads to problems concerning lack of precision and reliability, for example.

${ }^{6}$ This was pointed out to us by one of the anonymous reviewers.

${ }^{7}$ There might be cases in which the different conditions of adequacy will conflict. In these cases, we will have to choose between the conflicting conditions. See Feinberg (1984: 31f) for an example. We will discuss this further in the section on the five conditions below.

8 "Extensional adequacy" in Bradley (2012: 394).

${ }^{9}$ We can learn how social sustainability is used in many ways (see, for example, Murphy 2012: 17).

10 "Our common future" (the "Brundtland Report") has had a great impact on the discussion about sustainability. We therefore suspect that the key notion in this report, which states that "sustainable development is development that meets the needs of the present without compromising the ability of future generations to meet their own needs," will be at the core of the definition of "social sustainability". ${ }^{11} \mathrm{http}: / /$ www.healthscotland.com/uploads/documents/25059-Mind\%20the\%20 Gap.pdf.

${ }^{12}$ There is no pagination available for this encyclopedia entry, which is available here: https://plato.stanford.edu/archives/fall2018/entries/risk/ 
${ }^{13}$ Murphy (2012: 19) says something similar when he attempts to synthesize different types of policy objectives related to social sustainability.

${ }_{14}$ Weingaertner and Moberg (2014: 9-11) try to synthesize the findings from companies and products, as well as urban development, into key themes. This could be viewed as their attempt to find a common core for the concept, which is a bit more universal than a definition based only on one of the two areas.

${ }^{15}$ de Fine Licht came to know this in a workshop in the research project "The socially sustainable entrepreneur" where he worked with contractors on devising a tool for making the building process more socially sustainable. For more about the project and the tool see here: https://www.sbuf.se/Projektsida/?id=04616a4c-636f-4c61-aefedd1a85498978 (in Swedish).

${ }^{16}$ For a more thorough discussion of these two approaches, see Brülde $(1998,2000)$.

${ }^{17}$ Normative importance and the amorality desideratum are discussed, for example, in Bradley (2012: 395-396).

${ }^{18}$ We use the term "reason" rather than "should" because we might have other conflicting reasons of greater weight in favor of doing other things. For example, we might have environmental reasons for doing things that cause us to engage less with social values. This reasoning will be elaborated on in relation to the amorality condition.

${ }^{19}$ However, our evaluative intuitions may not always correspond to our semantic intuitions, and it is the evaluative intuitions (evaluative judgments) that are of interest in this section.

${ }^{20}$ Note that this paper discusses the structural nature of social sustainability. It is suggested that the definition should be compatible with different (reasonable) views on justice. What these views are is not part of this discussion, only that they are views of a particular kind.

${ }^{21}$ See Bradley (2012) and Harrosh (2012: 497), who discuss problems with views about "harm" that fail to satisfy either the condition of normative adequacy or the amorality condition. It can be argued that such views have the implausible implication either that harm is morally neutral or that harm is always morally wrong.

${ }^{22}$ Exactly how that should be done is a subject for further debate and structured argumentation.

${ }^{23}$ Another version of this idea is that the final weighing is about "sound judgment," communication, and leadership skills (Egan 2004). Since sound judgment and leadership skills cannot be the same everywhere, this speaks against having a universal definition of "social sustainability." Of course, these objections can be addressed in the same way.

${ }^{24}$ Something similar can be said about those who argue that we should have a plurality of sustainability concepts since we cherish plurality (Jacobs 1999). Again, it is probably not "any old notion" of social sustainability we cherish, and we could include in the definition that there should be room for plurality.

${ }^{25}$ We could interpret the idea that social sustainability is context-dependent, and hence not universal in its application, as a particularistic idea (Ghahramanpouri et al. 2013: 187, Dempsey et al. 2009). Weingaertner and Moberg (2014) say something similar when they argue that the concept of social sustainability should not, and cannot, be fully determined. 


\section{References}

Barron, L., \& Gauntlet, E. (2002, March). WACOSS housing and sustainable communities indicators project. In Sustaining our Communities International Local Agenda 21 Conference, Adelaide (pp. 3-6).

Beckerman, W. (1994) "Sustainable Development:" Is it a Useful Concept? Environmental Values 3 (3): 191-209. https://doi.org/10.3197/ 096327194776679700

Bevan, G., Hood, C. (2006) What's Measured is What Matters: Targets and Gaming in the English Public Health Care System. Public Administration 84 (3): 517-538. https://doi.org/10.1111/j.1467-9299.2006.00600.x

Bijker, W. E. (1993) Do Not Despair: There is Life after Constructivism. Science, Technology and Human Values 18 (1): 113-138. https://doi.org/10.1177/ 016224399301800107

Boström, M., Vifell, Å. C., Klintman, M., Soneryd, L., Hallström, K. T., Thedvall, R. (2015) Social Sustainability Requires Social Sustainability: Procedural Prerequisites for Reaching Substantive Goals. Nature and Culture 10 (2): 131156. https://doi.org/10.3167/nc.2015.100201

Boström, M. (2012) A Missing Pillar? Challenges in Theorizing and Practicing Social Sustainability: Introduction to the Special Issue. Sustainability: Science, Practice and Policy 8 (1): 3-14. https://doi.org/10.1080/15487733.2012.11908080

Bradley, B. (2012) Doing Away with Harm. Philosophy and Phenomenological Research 85 (2): 390-412. https://doi.org/10.1111/j.1933-1592.2012.00615.x

Bramley, G., Power, S. (2009) Urban Form and Social Sustainability: The Role of Density and Housing Type. Environment and Planning B: Planning and Design 36(1): 30-48. https://doi.org/10.1068/b33129

Brundtland, G. H. (1987) Report of the World Commission on Environment and Development: Our Common Future. New York, NY: United Nations.

Brülde, B. (1998) The Human Good. PhD Diss., University of Gothenburg,

Brülde, B. (2000) On How to Define the Concept of Health: A Loose Comparative Approach. Medicine, Health Care and Philosophy 3 (3): 303-306. https://doi.org/ 10.1023/A:1026517910117

Cozens, P., Love, T. (2015) A Review and Current Status of Crime Prevention Through Environmental Design (CPTED). Journal of Planning Literature 30 (4): 393-412. https://doi.org/10.1177/0885412215595440

Dancy, J. (2004) Ethics Without Principles. New York, NY: Oxford University Press. https://doi.org/10.1093/0199270023.001.0001

Davidson, M. (2010) Social Sustainability and the City. Geography Compass 4 (7): 872-880. http://dx.doi.org/10.1111/j.1749-8198.2010.00339.x

Dempsey, N., Bramley, G., Power, S., Brown, C. (2011) The Social Dimension of Sustainable Development: Defining Urban Social Sustainability. Sustainable Development 19 (5): 289-300. https://doi.org/10.1002/sd.417

Dillard, J., Dujon, V., King, M., eds. (2009) Understanding the Social Dimension of Sustainability. New York, NY: Routledge. https://doi.org/10.4324/ 9780203892978

Doran, G. T. (1981) There's a SMART Way to Write Management's Goals and Objectives. Management Review 70 (11): 35-36.

Egan, J. (2004) The Egan Review: Skills for Sustainable Communities. London, England: Office of the Deputy Prime Minister. 
Engelman R. (2013) Beyond Sustainababble. In: Worldwatch Institute (eds) State of the World 2013. Island Press, Washington, DC. https://doi.org/10.5822/978-161091-458-1_1

Eken, A., Magnusson, J., Hildesson, A., Molnar, S., De Fine Licht, K. (Forthcoming) Rätt verktyg för jobbet? En översikt över verktyg för social hållbarhetsanalys $i$ städer. Mistra Urban Futures Papers.

Eurostat. All of the reports are available here: http://ec.europa.eu/eurostat/web/sdi/ overview

Feinberg, J. (1984) The Moral Limits of the Criminal Law. Vol. 1, Harm to Others. New York, NY: Oxford University Press.

Ghahramanpouri, A., Lamit, H., Sedaghatnia, S. (2013) Urban Social Sustainability Trends in Research Literature. Asian Social Science 9 (4): 185. https://doi.org/10.5822/978-1-61091-458-1_1

Gustavsson, E., Elander, I. (2013) Social hållbarhet inte bara 'sustainababble?': Från mångtydig vision till analytiskt redskap vid uppföljning av stadsbyggnadsprojekt. Orebro, Sweden: Orebro University.

Hansson, S. (2018) Risk. The Stanford Encyclopedia of Philosophy (Fall 2018 Edition), Edward N.Zalta (ed.), https://plato.stanford.edu/archives/fall2018/ entries/risk/.

Harrosh, S. (2012) Identifying Harms. Bioethics 26 (9): 493-498. https://doi.org/ 10.1111/j.1467-8519.2011.01889.x

Haybron, D. M. (2016) Mental State Approaches to Well-Being. In The Oxford Handbook of Well-Being and Public Policy, edited by Matthew D. Adler, Marc Fleurbaey, 347-378. New York, NY: Oxford University Press. https://doi.org/ 10.1093/oxfordhb/9780199325818.013.11

Herlitz, A., Horan, D. (2016) Measuring needs for priority setting in healthcare planning and policy. Social Science \& Medicine 157: 96-102. https://doi.org/ 10.1016/j.socscimed.2016.03.002

Jordan, A. (2008) The governance of sustainable development: taking stock and looking forwards. Environment and Planning C: Government and Policy 26 (1): 17-33. https://doi.org/10.1068/cav6

Kagan, S. (1989) The Limits of Morality. Oxford, England: Oxford University Press.

McMahan, J. (2000) Moral intuition. In The Blackwell Guide to Ethical Theory, edited by H. LaFollette and I. Persson,103-120. Hoboken, NJ: Blackwell Publishers Ltd. https://doi.org/10.1111/b.9780631201199.1999.00001.x

Mazumdar, S., Learnihan, V., Cochrane, T., Davey, R. 2017. The Built Environment and Social Capital: A Systematic Review. Environment and Behavior 50 (2): 119158. https://doi.org/10.1177/0013916516687343

McKenzie, S. (2004) Social Sustainability: Towards Some Definitions. Magill, South Australia: University of South Australia.

Moula, P., Sandin, P. (2015) Evaluating Ethical Tools. Metaphilosophy 46 (2): $263-$ 279. https://doi.org/10.1111/meta.12130

Murphy, K. (2012) The Social Pillar of Sustainable Development: A Literature Review and Framework for Policy Analysis. Sustainability: Science, Practice and Policy 8 (1): 15-29. https://doi.org/10.1080/15487733.2012.11908081

Pitts, A. (2004) Planning and Design Strategies for Sustainability and Profit. Architectural Press.

Power, M. (1997) The Audit Society: Rituals of Verification. Oxford, England: Oxford University Press. 
Rawls, J. (1971) A Theory of Justice. Cambridge, MA: Harvard University.

Roemer, J. E. (1993) A Pragmatic Theory of Responsibility for the Egalitarian Planner. Philosophy \& Public Affairs 22 (2): 146-166.

United Nations Department for Policy Coordination, and Sustainable Development (UNSD). 1996. Indicators of Sustainable Development: Framework and Methodologies. New York, NY: United Nations.

Tahvilzadeh, N. (2015) Socialt hållbar stadsutveckling? Stadsdelsnämnderna. stadsutvecklarrollen och sociala konsekvensanalyser i planeringen av Göteborgs stad. Report 133 Public Administration. Gothenburg, Sweden: University of Gothenburg. Available here: https:/gupea.ub.gu.se/bitstream/2077/41115/1/ gupea_2077_41115_1.pdf

Temkin, (2012) Rethinking the Good: Moral Ideals and the Nature of Practical Reasoning. New York, NY: Oxford University Press. https://doi.org/ 10.1093/acprof:oso/9780199759446.001.0001

Tännsjö, T. (2015) Taking Life -Three Theories on the Ethics of Killing. Oxford U P: Oxford. https://doi.org/10.1093/acprof:oso/9780190225575.001.0001

Vallance, S., Perkins, H. C., Dixon, J. E. 2011. What is Social Sustainability? A Clarification of concepts. Geoforum 42 (3): 342-348. https://doi.org/ 10.1016/j.geoforum.2011.01.002

Weingaertner, C., Moberg, A. (2014) Exploring social Sustainability: Learning from Perspectives on Urban Development and Companies and Products. Sustainable Development 22 (2): 122-133. https://doi.org/10.1002/sd.536 